Article

\title{
Implementing TRIZ with Supply Chain Management in New Product Development for Small and Medium Enterprises
}

\author{
Yun-Sheng Lin $(\mathbb{D}$ and Mingchih Chen * \\ Graduate School of Business Administration, Fu Jen Catholic University, New Taipei City 24205, Taiwan; \\ marklin.kunnex@gmail.com \\ * Correspondence: 081438@mail.fju.edu.tw
}

Citation: Lin, Y.-S.; Chen, M Implementing TRIZ with Supply Chain Management in New Product Development for Small and Medium Enterprises. Processes 2021, 9, 614. https://doi.org/10.3390/pr9040614

Academic Editor: Chih-Te Yang

Received: 8 March 2021

Accepted: 30 March 2021

Published: 31 March 2021

Publisher's Note: MDPI stays neutral with regard to jurisdictional claims in published maps and institutional affiliations.

Copyright: (c) 2021 by the authors. Licensee MDPI, Basel, Switzerland. This article is an open access article distributed under the terms and conditions of the Creative Commons Attribution (CC BY) license (https:/ / creativecommons.org/licenses/by/ $4.0 /)$.

\begin{abstract}
Due to the impact of globalization, the competition between enterprises has become fierce and led the supply chains of many industries to be reorganized. One of the consequences is that the operation of many small and medium enterprises (SMs) had become very difficult. Hence, many of SMEs in Taiwan have gone bankrupt and some of them have moved to other places where they have lower production costs, in order to survive; this not only hollowed out the industries but also disconnected the supply chains in their mother countries. Because Taiwan's SMEs are generally poor in innovation, this study explored the implementation of the theory of inventive problem-solving (TRIZ) with alignment of new product development (NPD) and supply chain management (SCM) to strengthen the innovation and productivity of new products, so that SMEs can refer to its use to aid sustainable business operation. We considered an SME in Taiwan as a case to study and investigate the strategies that it employed to achieve survival and sustainability. By examining the practical applications of the NPD of the case company, which was based on the TRIZ and NPD SCM alignment, we found that value-added products may be created despite unfavorable industry environments, by implementing and coordinating the TRIZ and three product-related variables, namely innovating, modularity, and variety. This study explored practical alternatives for SMEs to develop various value-added products that meet customers' changing requirements and succeed in competitive markets to achieve a sustainable business operation. Considering SMEs are crucially important to the economic equality and development of countries and that SMEs may only survive for a short time when operating in changing supply chain environments, this study can be used as a reference for the management of SMEs and future academic research in related fields.
\end{abstract}

Keywords: new product development; theory of inventive problem-solving; supply chain; small and medium enterprises; innovative; product modularity; sustainability

\section{Introduction}

Globalization has increased the territorial reach of enterprises. Taiwan's small and medium enterprises (SMEs) had been enjoying the benefits brought about by globalization; however, in recent years, most of these SMEs have suffered due to the considerable competition from foreign companies, especially Chinese companies who can achieve low production costs and large-scale production. Taiwanese SMEs are constrained by the size of the Taiwanese market; therefore, most of the SMEs can only export their products to foreign countries or work as original equipment manufacturing (OEM), or original design manufacturing (ODM) subcontractors for global corporations. Thus, the marketing autonomy of Taiwanese SMEs is controlled and the high added values created by marketing are held by foreign buyers or global corporations. Moreover, Taiwanese SMEs earn only meager profits within their supply chains. This phenomenon has led to difficulties in the management of Taiwanese SMEs, who still face competition in terms of price from the rapidly developing Chinese and Southeast Asian enterprises. Because numerous SMEs have moved out of Taiwan to reduce production costs, some of traditional industry supply chains have been 
disconnected or even totally hollowed out, which has caused an increasing number of problems for SMEs that still operate in Taiwan. The aforementioned unfavorable factors have forced SMEs that operate in Taiwan to adopt various response strategies, such as new product development (NPD), supply chain restructuring, technological upgrading, and corporate transformation for survival and sustainability. Because Taiwan's SMEs are generally poor in innovation, this study explored the implementation of TRIZ with alignment of NPD and SCM to strengthen the innovation and productivity of new products so that the SMEs can use it for the purpose of sustainable business operation.

NPD and supply chain management (SCM) allow enterprises to respond to new demands in a responsive manner [1]. NPD is the process of transforming a market opportunity and a set of assumptions about product technology into a marketable product [2,3]. The ability of enterprises to compete and survive in the market is connected to their ability to innovate, which includes their ability to design, manufacture, and deliver new products and services to the market [4-6]. SCM refers to the approach for designing, organizing, and executing all the supply chain activities, ranging from planning to distribution along the entire value chain, including the network of suppliers, manufacturers, and distributors [7,8]. Therefore, NPD and SCM are related to each other because the supply chain produces and distributes products, which are the output of the product development process. The appropriate management of supply chains by SMEs is crucial for meeting the varied needs of a changing environment.

In this study, we investigated the strategies and approaches used by a local Taiwanese SME to implement the theory of inventive problem-solving (TRIZ) in NPD with the alignment of NPD and SCM for overcoming the difficulties caused by the disconnection or hollowing out of its supply chains in Taiwan. This research identified three critical factors: innovation, product modularity, and variety that enable new products with high added value to increase company competitiveness and meet changing customer requirements. This increase in competitiveness and ability to meet changing customer requirements can help a company survive and sustain its business in Taiwan.

\section{Research Background}

\subsection{Theory of Inventive Problem-Solving}

The competitive advantage of a company lies in successive product innovations in a global market with an increasing variety of user demands [9]. The key to product innovation is to set up a conceptual innovation design model for designers to discover, identify and solve system conflicts of products [10]. Currently, many innovative design techniques are available to assist designers in the development of products. Among them, the TRIZ is mostly used at the conceptual design stage to generate design concepts and solve problems [11-14].

The TRIZ was developed by Genrich Altshuller in the 1940s to solve most engineering problems innovatively. To develop the TRIZ, Altshuller screened over 200,000 patents, from which he extracted 40,000 innovative patents to obtain three innovative methods. The first method involved extracting innovative principles for solving engineering problems by using a contradiction matrix. In the second method, the separation principle was used to separate certain effects. The third method involved highlighting the deficiencies of a design through substance-field (Su-field) analysis [15].

The contradiction matrix is the core component of TRIZ tools; it comprises 39 engineering parameters and 40 inventive principles [16]. To apply the contraction matrix, design problems must be first transformed into TRIZ problems by using the 39 standard engineering parameters as a reference. The transformed problems are identified and classified into technical and physical contradictions. The 40 inventive principles provide definite guidance to designers for solving technical contradictions. These inventive principles can be used to solve the TRIZ problems. The solutions obtained from the TRIZ can then be used to solve the relevant design problems. The conceptual schema of the TRIZ in solving problems is displayed in Figure 1. 


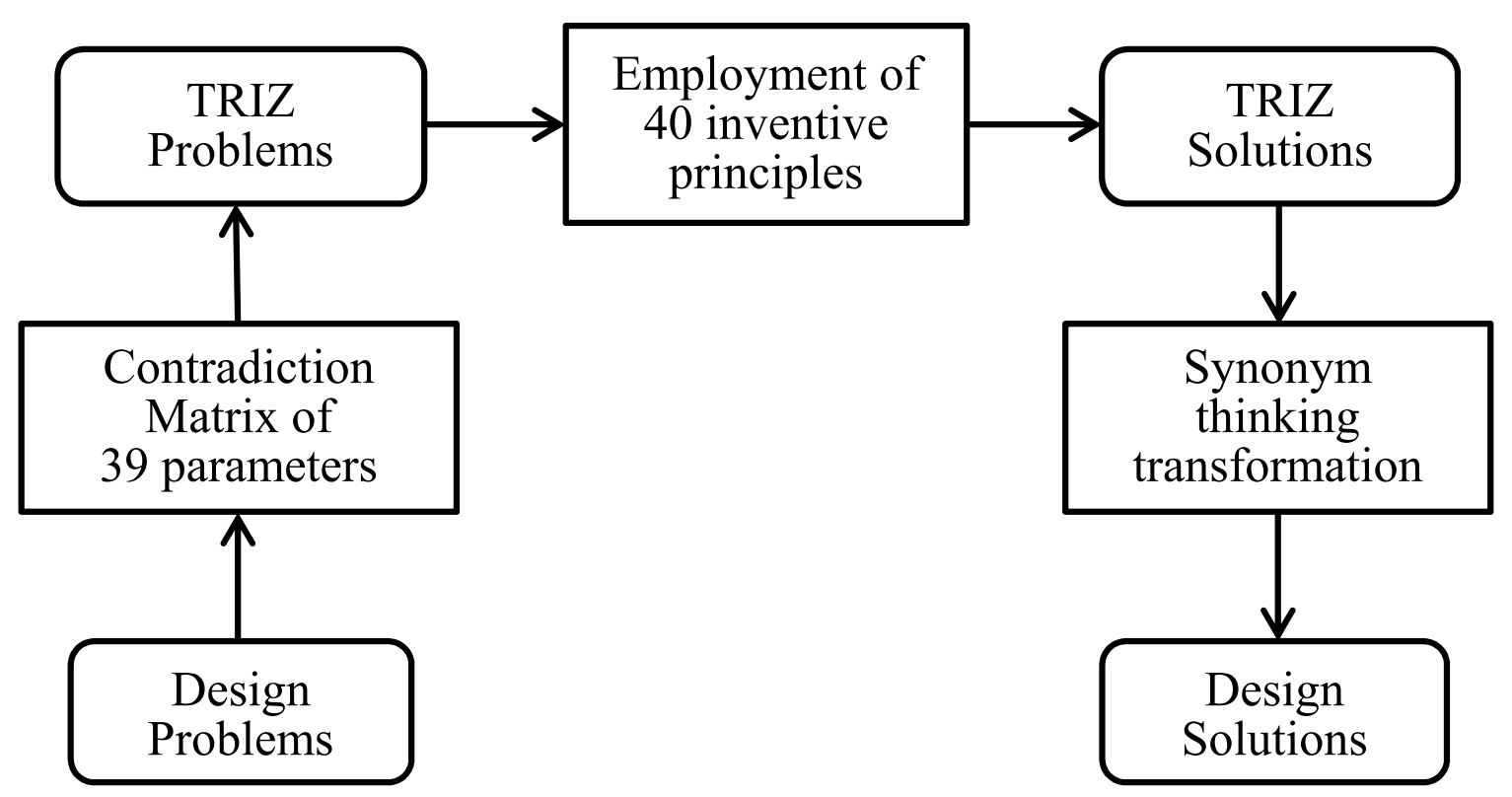

Figure 1. Conceptual schema of the theory of inventive problem-solving (TRIZ).

The elimination of contradictions is a fundamental concept of the TRIZ. The TRIZ recognizes two types of contradictions: technical and physical contradictions. Technical contradictions occur when one engineering parameter in a system improves while another worsens (e.g., increases or decreases in brightness and energy consumption or cost and quality). Physical contradictions represent a system with two opposite parameters (e.g., cold and hot or long and short). These physical contradictions can be eliminated using four basic types of separation principles: separation in time, separation in space, separation on condition, and transition to an alternative system. The aforementioned contradictions can also be solved using the 40 inventive principles of the TRIZ [17].

Because the TRIZ looks for sources of innovation in the system itself and not in the individuals or the organizations surrounding it, its processes for problem solving can be managed and guided in many different respects. Extensive research has been conducted on the TRIZ. Some studies have attempted to customize, test, validate and analyze the use of the 40 inventive principles of the TRIZ in non-technical and business-related areas [18-22]. Research has been conducted to extend the TRIZ for resolving any type of problem, and not only those problems related to the evolution of technical systems [23]. Research has indicated that the TRIZ can provide users with some direction of thought regarding SCM [24].

\subsection{Alignment of NPD and SCM}

In many companies, NPD is considered a key strategic activity that is critical to longterm success. SCM encompasses the planning and management of all activities involved in sourcing and procurement, conversion, logistics management activities, coordination, and collaboration with channel partners. Being the first enterprises to market new products at a reasonable cost is crucial [25], and SCM needs to be involved in a proper way to achieve the right balance between responsiveness and efficiency for various types of markets, consumers, and products [1].

Not coordinating NPD and SCM may hinder a company's ability to deliver products in an innovative and responsive manner, which is becoming increasingly important in mature and highly competitive markets [26]. Studies on approaches to align NPD and SCM are either NPD- or SCM-oriented, as presented in Table 1 [27]. 
Table 1. Main approaches for the alignment of new product development (NPD) and supply chain management (SCM), adapted from [27].

\begin{tabular}{cccc}
\hline $\begin{array}{c}\text { Approaches for } \\
\text { NPD-SCM Alignment }\end{array}$ & $\begin{array}{c}\text { Supply Chain-Related } \\
\text { Variable }\end{array}$ & $\begin{array}{c}\text { Product-Related } \\
\text { Variable }\end{array}$ & Literature References \\
\hline NPD-oriented Approaches & $\begin{array}{c}\text { 1. SC structure } \\
\text { 2. SC Costs }\end{array}$ & $\begin{array}{c}\text { 1. Architecture } \\
\text { 2. Bill-of-materials (BOM) }\end{array}$ & [28-32] \\
\hline $\begin{array}{c}\text { SCM-oriented Approaches } \\
\text { (model 1) }\end{array}$ & $\begin{array}{c}\text { 1. SC strategy definition } \\
\text { (product- and market-related variables) }\end{array}$ & $\begin{array}{c}\text { 1. Product innovation } \\
\text { 2. Modularity } \\
\text { 3. Variety }\end{array}$ & [7,8,33] \\
\hline $\begin{array}{c}\text { SCM-oriented Approaches } \\
\text { (model 2) }\end{array}$ & $\begin{array}{c}\text { 1. SC structure } \\
\text { 2. SC operations } \\
\text { 3. SC costs } \\
\text { 1. Product structure } \\
\text { 2. Modularity } \\
\text { 3. Variety }\end{array}$ \\
\hline
\end{tabular}

The NPD-oriented approach anticipates the supply chain constraints in the early stage of product development. It considers the product architecture or bill-of-materials for decision support. All relevant costs, such as transportation and inventory costs in the supply chain are first expressed as a function of the product structure. The cost function is then optimized to determine the best product structure for a given supply chain [28-30]. This approach may be called "design for SCM" [30].

The SCM-oriented approach considers that the product and its characteristics are given. Two SCM-oriented models exist. The first model defines supply chain strategy on the basis of product- and market-related variables, such as level of innovation, demand variability, variety level, and demand volumes $[8,33,44,45]$. The second model investigates the manner in which supply chain design is affected by the product structure. These aforementioned two models consider modularity and product variety [34]. Therefore, the following three product-related variables should be considered when applying an SCM-oriented approach for the alignment of NPD and SCM:

(1) Product innovation: The level of innovation depends on the type of innovation project. Wheelwright and Clark [3] defined three types of new product projects: breakthrough, platform, and derivative projects. Breakthrough projects require the highest level of investments and involve the creation of completely new products. Platform projects aim to develop architectural innovations, and derivative projects give rise to a new module or component innovations. Derivative modification involves a low level of innovation.

(2) Product modularity: Modularity encompasses the decomposition of a complex product design into independent modules and the ability to adapt to a new configuration easily. Product components are shared across different product lines and assembly parts, which results in a considerable reduction of design efforts and inventory costs [46]. Modularity also provides high product variety and facilitates innovation, which allows a manufacturer to cope better with changing environments [47,48].

(3) Product variety: Product variety has been studied and classified into two dimensions: the breadth of a product range at a given time and the rate at which a firm replaces the existing products [49]. Pil and Holweg [50] distinguish between external and internal variety. External variety denotes the level of choice available to the customers, whereas internal variety is experienced inside manufacturing and internal supply chain operations.

Large firms usually have a strong influence on the supply chains due to their market position; thus, they are flexible in forming strategic alliances with suppliers and distributors. Therefore, most large firms prefer to adopt an NPD-oriented approach for NPD-SCM alignment because they exert substantial power and influence over their suppliers. By contrast, an SME has a relatively restricted scope of influence on supply chains [51,52]. SMEs are more likely to have a differentiation advantage than a cost advantage, mainly 
because of their scale, their scope, and learning economies in industries [53]. SMEs focus on developing unique competencies and strive for effective customer and supplier management [54]. Due to their relatively flat structure and relatively few management levels, SMEs can easily change their organizational culture [55] and thus changes their implementation of SCM. Therefore, most SMEs must adopt an SCM-oriented approach to coordinate the product-related variables of their NPD with their SCM strategies appropriately for responding to possible changes in supply chains.

\subsection{Implementation of the TRIZ in NPD with NPD-SCM Alignment}

The survival and growth of SMEs may depend on the manner in which they effectively allocate resources according to their strategic focus. Strategic focus broadly refers to the manner in which SMEs compete within supply chains in terms of either low-cost or valueadded operations (e.g., new product and service development) [56]. Firms with a "low-cost" focus tend to produce mature products; consequently, their market potential may not be growing, in contrast to firms with a "value-added" orientation design and deliver new products or services to meet changing customer requirements.

The aim of this research was to determine approaches for an SME to employ the TRIZ with the SCM-oriented approach for NPD-SCM alignment to create value-added products to satisfy customers and competing in the market. To achieve this aim, the practical applications of the NPD process of the case company were examined to understand how an SME can employ the TRIZ method and an SCM-oriented approach for NPD-SCM alignment to produce value-added products to satisfy customers and compete in the market. The research questions are as follows:

(1) What are the linkages between TRIZ and the NPD-SCM alignment during NPD?

(2) How does one implement and coordinate TRIZ and the three product-related variables of the SCM-oriented approach-innovation, modularity, and variety for new valueadded products?

\section{Material and Method}

This research aimed to investigate and identify the critical success factors in the strategies that a Taiwan SME employs to help align their innovative product development with SCM for business sustainability. The research is mainly inductive [57] because it attempts to form explanations and descriptions based on the observations of one singlecase study. This research adopts the in-depth interview method, which is a type of interview with an individual that aims to collect detailed information beyond initial and surface-level answers. In-depth interview is a qualitative data collection method that involves direct one-to-one engagement with individual participants. All the data and information in this study were obtained through in-depth interviews with the persons in charge of the company's new product development and business, respectively. The data range covered from 2001 to 2021, the case company's new product development of men's hair trimmers, and changes of the related supply chains, as well as their corresponding strategy and management measures.

The case company is an SME in Taiwan that specializes in manufacturing various small personal electric appliances, such as electric toothbrushes, hair clippers, trimmers, and shavers. The case company has been in existence for more than 30 years. It mainly exports its products to developed countries, such as the United States, Japan, and European countries. The aforementioned company has worked as a contracted original design manufacturer for several global brands for many years. The foreign customers of the case company expect it to develop innovative products yearly to meet the various market demands.

The case company was selected because although some of its supply chains had disintegrated, it still remained in business in Taiwan and is currently sustainable and prospering. Until about 2000, almost all types of electric and electronic parts and components used in Taiwan were conveniently provided by the local suppliers and supply chains. However, 
after China openef itself to the global market in the 1980s, many Taiwanese factories began to move to China in order to reduce costs for competition. This migration accelerated after the financial crisis of 2008, when almost all the electric and electronic industries moved out of Taiwan. This phenomenon led to the supply chains of Taiwan's traditional electric and electronic industries being nearly hollowed out. In such an unfavorable environment, the case company still manages to survive in Taiwan and continuously grew to achieve business sustainability; therefore, this company is worth researching.

\section{Findings}

\subsection{Original Relationships between the NPD and Supply Chains of the Case Company}

Figure 2 displays the original relationships between the investigated company's NPD and their supply chains by early 2000, when most of the suppliers associated with their main products were located in Taiwan. This company relied on professional suppliers in many fields, except for manufacturers of plastic injection molding parts which are produced in-house. The main products of the investigated company are small electric appliances for personal use, such as electric clippers, electric trimmers, electric shavers, electric toothbrushes, and electronic novelties. Therefore, all the products of the company were designed and developed in accordance with customer requirements and should satisfy the demands of target markets. Because the investigated company obtained all types of parts and the information on them from local Taiwanese suppliers in the early 2000s, it employed the stage-gate process and integrated design approach for its NPD and production. Moreover, because almost all its suppliers were located in Taiwan, the investigated company did not focus on the lead time and costs of transportation and storage; therefore, they did not pay considerable attention to SCM during the aforementioned period.

\subsection{Case Company's NPD Process Based on the TRIZ and NPD-SCM Alignment}

Many researchers have suggested that NPD must be structured into a stage-gate process. Moreover, best-practice firms implement these processes to a greater extent than do other firms [58,59]. For example, the process developed by Ulrich and Eppinger [59] consists of six phases: including planning, concept development, system-level design, detail design, testing and refinement, and production ramp-up. Many studies encouraged user involvement in the early stage of product development. Most studies pay attention to understanding user needs and the context of uses [60]. Cooper and Kleinschmidt [61] describe the stage-gate process as dividing NPD into a predetermined set of stages, each of which consists of prescribed, multifunctional, and parallel activities with gates that are quality control checkpoints.

Different researchers have suggested different numbers and titles of stages and gates; however, the supply chain has never been mentioned as a main function or area. Although some typical supply chain activities are discussed within the manufacturing function of the stage-gate approach (e.g., identification of suppliers for key components), they are rather considered at too late a stage, moreover, the depth and breadth of the assessment is insufficient to cope with changes in the supply chains.

Some researchers argue that stage-gate processes are excessively linear and rigid for managing innovative projects in a competitive and global market [62,63]. This criticism has led to the proposal of new stage-gate processes over time; however, no research has shown that only employing the stage-gate process may help in the development of products with innovation.

Integrated design is a comprehensive holistic design approach that merges specialisms that are usually considered separately, similar to expert opinion and brainstorming methods. The integrated design method attempts to consider all the factors and modulations involved in a decision-making process [64], such as designing a product (or a family of products) and the assembly system that would produce it $[65,66]$, or designing an electronic product considering both hardware and software aspects. The need for integrated design arises when different specialisms are dependent on each other or "coupled", however, 
when a drastic change in supply chains occurs, such as when a supply chain is disconnected or hollowed out, problems may arise when using the integrated design method for NPD.

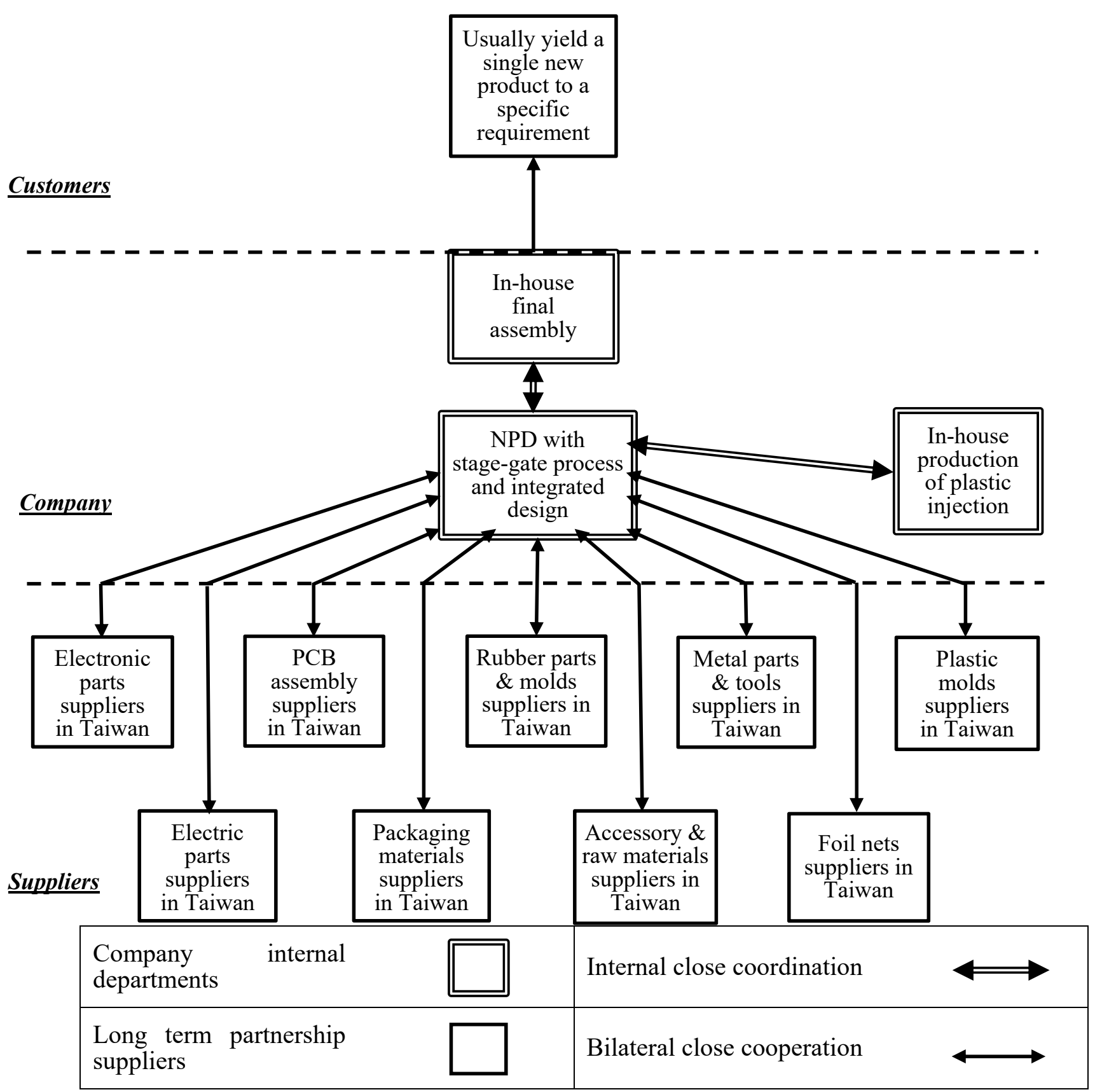

Figure 2. Case company's original supply chains by early 2000.

To overcome the aforementioned problems and the drawbacks in employing the stagegate process and integrated design for NPD, the investigated company devised a unique NPD process that includes a TRIZ method and a procedure for aligning NPD with changing SCM (Figure 3). By using this unique NPD process, the investigated company could overcome the unfavorable industry environments in Taiwan after the 2008 financial crisis. 


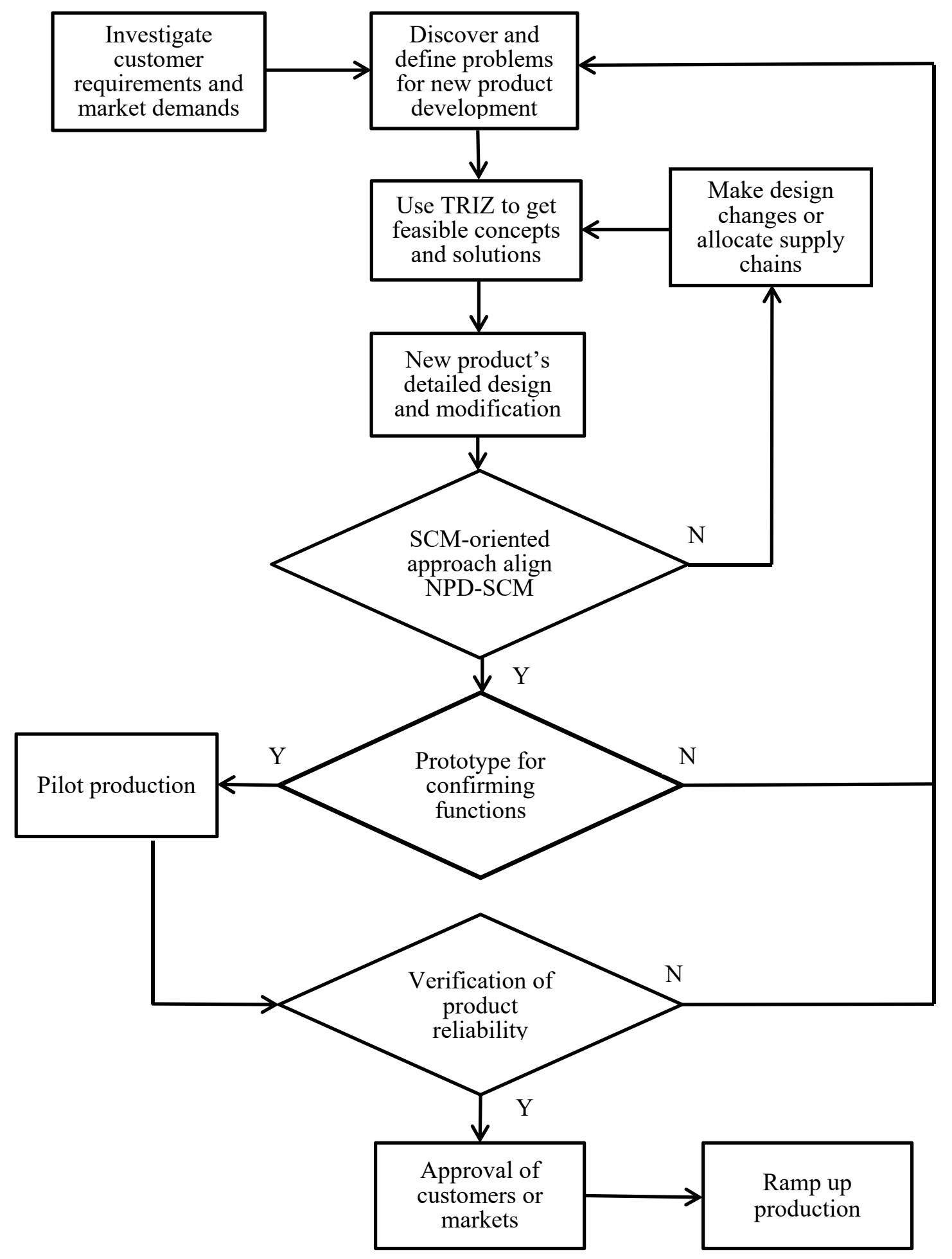

Figure 3. The investigated company's NPD process based on the TRIZ and NPD-SCM alignment.

\subsection{Practical Applications of the Case Company's NPD Process}

Around 2000, electric grooming devices for men, such as hair clippers, trimmers, body hair removal appliances, and shavers have become popular in many developed countries. Due to the considerable potential of the men's grooming market, the case company decided to manufacture the aforementioned products. The case company did not find it difficult to enter the aforementioned field because they had many years of experience in the developing and producing various types of electric toothbrushes and electronic novelties. However, 
the key to being a successful manufacturer of the aforementioned products was obtaining a comprehensive supply of precision blades and foil nets for the trimmers and shavers. The supply chains for related parts and components in Taiwan during the aforementioned period were fully formed, the company faced no problem in acquiring sufficient support from local suppliers to develop its products and subsequently mass produce them.

In the early 2000s, the case company was approached by one of their customers to develop a nose hair trimmer. The customer required that the new product be equipped with an innovative and reliable cutting system and different from those already existing in the market. The case company first analyzed several representative products in the market and found that these products contained similar inner blade sets (Figure 4a), comprising seven parts, including inner blades, springs, pins, and a plastic supporter. Hair caught by the cutting splits of the outer blade was cut through the rotation of the inner blade set inside the outer blade. Through testing, the case company determined the following main problems with the cutting systems of existing products: unstable, poor, and unreliable cutting performance. The project team of the case company transformed the practical design problems into TRIZ problems to obtain solutions. They investigated the technical contradictions existing in all 39 engineering parameters of the TRIZ to establish a layout of the contradiction matrix. By using the 40 principles of the TRIZ, the aforementioned team determined the concepts for designing an innovative inner blade set (Figure $4 \mathrm{~b}$ ).

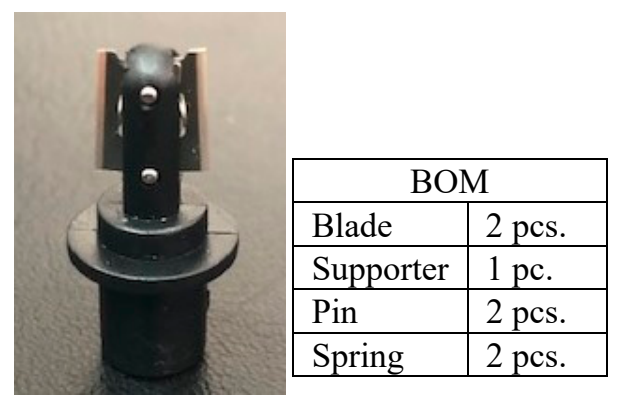

(a)

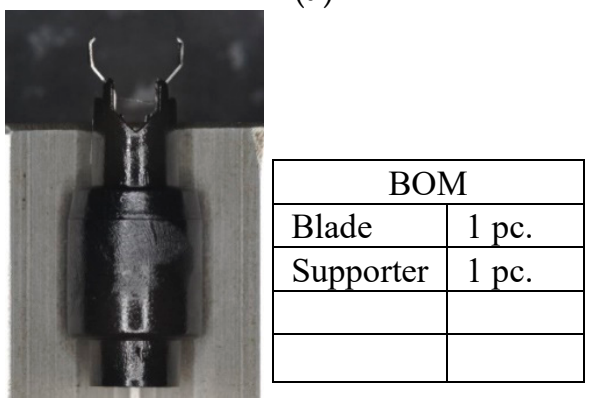

(b)

Figure 4. Comparison of inner blade sets. (a) Typical inner blade set in market; (b) Innovative inner blade set.

The new cutting system (Figure 5) offered a stable cutting performance every time because the structure of its innovative inner blade set was so simple that it excluded the aforementioned problems of existing products in the market. The innovatively designed inner blade set was highly cost-effective because, unlike the existing trimmers in the market, which had several moving parts, the case company's trimmer had only two parts. This design also reduced problems associated with cutting performance, which were caused by improper use and negligence in cleaning by consumers. 


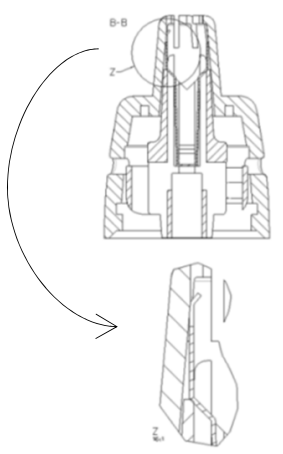

(a)

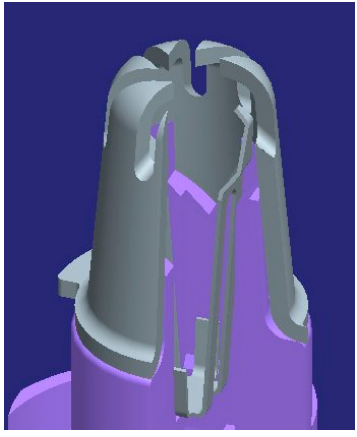

(b)

Figure 5. Cross-section of the new cutting system with an innovative inner blade set. (a) Drawing; (b) illustration.

The new nose hair trimmer was highly popular due to its excellent functions. Inquiries were received about the trimmer from many customers worldwide. To avoid competition among customers located in the same country or market and to respond to customer requirements for product differentiation, the company continuously developed a variety of electric nose trimmers. Among them, the self-washable nose hair trimmer (Figure 6) was one of the most popular items and was patented in many countries (Taiwan patent No. M282554; United States patent No. US7,152,323 B1; and China patent No. ZL 20052 00285267). The difference between the aforementioned item and previously developed nose hair trimmers was the inclusion of a propeller with an inner blade supporter (Figure $6 b$ ) and additional holes on the outer blade frame only. Through the experience in developing a series of nose hair trimmers, the company found that integrating the concept of modularity of SCM with the TRIZ approach facilitates the development of various innovative products, while saving cost and shortening the time required for the product to reach the market.

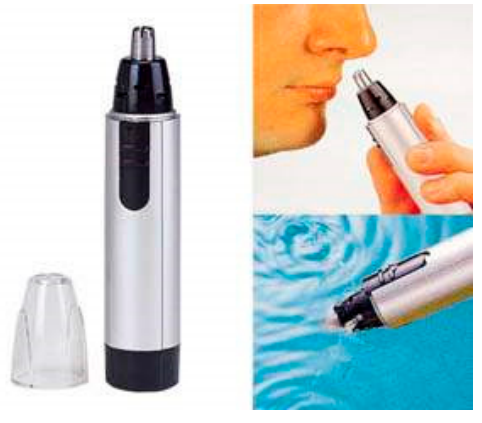

(a)

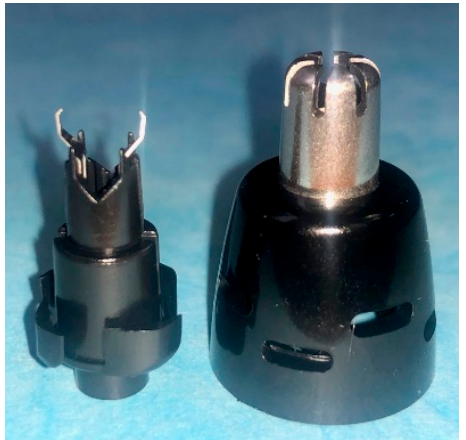

(b)

Figure 6. Self-washable nose hair trimmer. (a) Illustration of self-wash function; (b) Inner blade supporter with propeller.

In the early 2000s, electric grooming devices for men only had a single function only. For example, electric clippers were used only for cutting hairs, nose trimmers were used only for trimming nasal hairs, and shavers were used solely for shaving. Not long after the aforementioned new cutting system was developed, an American customer required help in developing a facial trimmer for men that had features different from those of other brands. The case company again adopted modularity concept and TRIZ approach to develop an innovative product, namely 2-in-1 trimmer for men (Figure 7). This newly developed product had one power unit and two changeable trimming heads, for trimming the beard, mustache, sideburns, and nose and ear hairs. The aforementioned product was the world's first personal electric grooming device designed using the concept of modularity. This new 
product was soon imitated by other competitive dealers and manufacturers. Unfortunately, the case company did not apply for a patent to protect the aforementioned design.

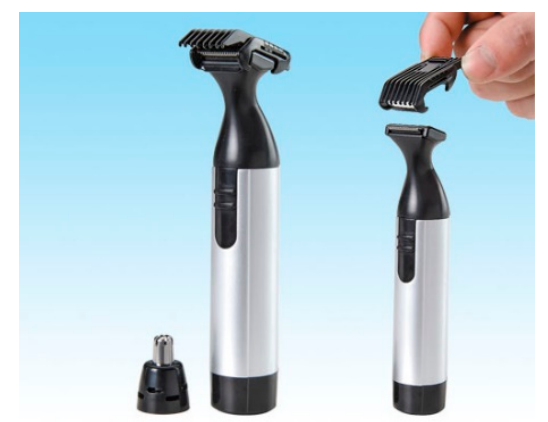

Figure 7. Wet/dry 2-in-1 men's trimmer for men produced by the case company.

To remain ahead of its competition, the case company continued to develop new products, such as 4-in-1 men's groomer (Figure 8a) that included the shaving and eyebrow trimming functions. This product was widely accepted by major customers worldwide. Consequently, a rechargeable type of the aforementioned product (Figure $8 b$ ) had also been developed. However, because some manufacturers belonging to related industries had moved out of Taiwan gradually after 2008, and subsequently, the supply chains for precision blades and foil nets were broken. Moreover, the supply chains for traditional consumer electric and electronic industries had hollowed out. To respond to the changes in the supply chains in its NPD process, the case company adopted various measures, such as backward integration, supply chain adjustment, and organization change for aligning NPD and SCM.

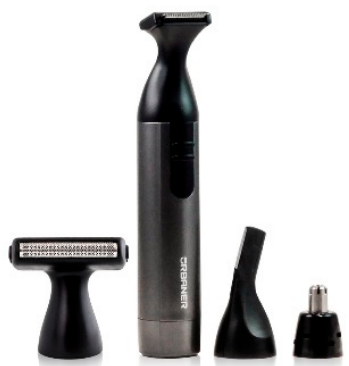

(a)

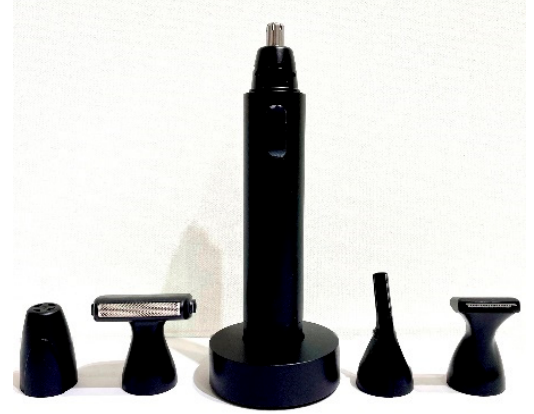

(b)

Figure 8. Wet/dry 4-in-1 groomer for men. (a) Battery- operated type; (b) Rechargeable type.

\subsection{Case Company Aligned NPD-SCM in Response to Changes in Supply Chains}

In response to the hollowed out supply chains of electric and electronic industries, as well as the broken supply chains of some traditional industries, such as those of precision blades, foil nets, and rubber parts, the case company established an SCM unit to manage some of their functions, such as suppliers sourcing, enquiries, specification and information acquisition, procurement, subcontract manufacturing, and shipment. Moreover, to remain ahead of its competition, the company decided to implement backward integration to set up its own processing plant for manufacturing precision blades and foil nets to upgrade the quality and technical contents of its products. By streamlining the organization to reduce costs and concentrating resources on core products, the case company outsourced the production of previously in-house-manufactured plastic injection molding parts to contractors.

Figure 9 shows the current relationship between the case company's NPD and supply chains. Although the case company remained in Taiwan, where the industrial environment 
was unfavorable to it, it could adjust its NPD according to changed supply chains in a timely manner by employing the TRIZ and NPD-SCM alignment in its NPD process to launch value-added new products continuously to meet the diverse requirements of customers and markets.

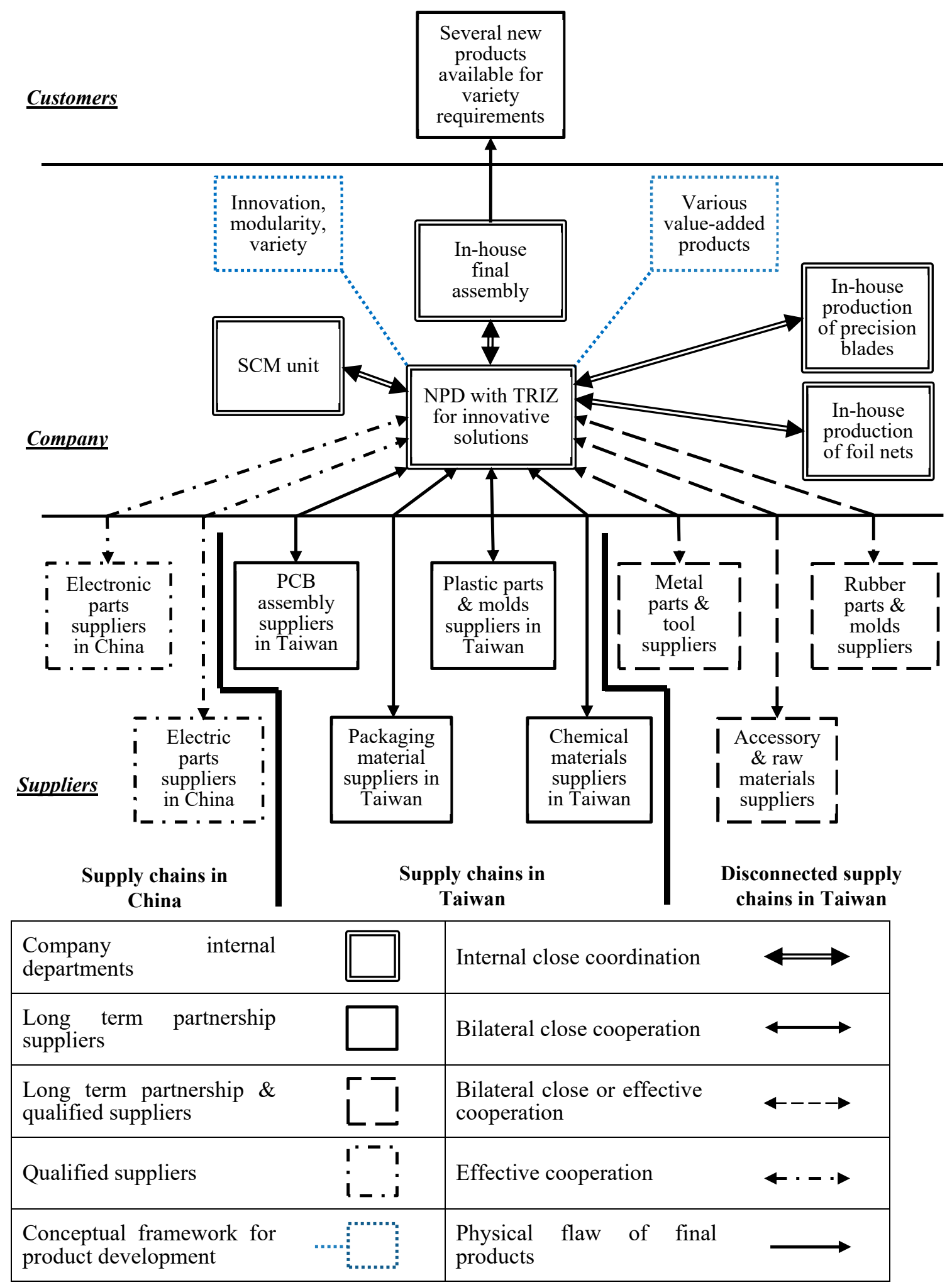

Figure 9. Case company's current supply chains. 


\section{Discussion and Conclusions}

Through an investigation of the case company that manufactures various personal trimmers for men, we found that despite the drastic changes in its supply chains, the company was able to survive and continue its business operation in Taiwan. The company could survive because its NPD process was based on the TRIZ and an SCM-oriented approach for NPD-SCM alignment, which enabled the development of valuable concepts for innovative designs on aspects of product modularity and variety. The combination of the aforementioned concepts enabled the development of various value-added products to meet with the diverse requirements of customers and the market.

The TRIZ is a useful and effective tool for conceiving innovative concepts for NPDs. However, to use the TRIZ method, people with extensive practical experience are required so that it will not flow into failure or pure fantasy. Moreover, although using the TRIZ method may assist the development of innovative products, this product may not be suitable for practical use because of problems that may occur in the reliability and productivity of a product or dissatisfaction of customers. Therefore, in practice, a newly developed product must undergo function confirmation and reliability verification before ramping up production.

This research confirmed that an SME can survive and sustain itself in an unfavorable supply chain environment by adopting an NPD process that includes the TRIZ and an SCM-oriented approach for NPD-SCM alignment. Integrating the TRIZ method with the NPD process and the SCM-oriented approach may help increase the level of product innovation considerably, contribute significantly to the appropriate achievement of product modularity and variety, and consistently benefit the development of various new valueadded products. This process facilitates the development of new value-added products to increase company competitiveness and satisfy customers. The results of this study can be used as a reference by other SMEs, and for future research in related fields.

However, some questions remain unanswered. These questions include whether the TRIZ and NPD-SCM alignment can be employed for SMEs in different industries, whether it is workable in case of most supply chains were seriously disconnected or hollowed out, whether using backward integration to compensate for the deficiencies of supply chains is worthwhile despite the high additional investment and risk, and what strategies should be adopted by an enterprise if they intend to use their own brand for marketing. Further studies must be conducted to answer these questions. The research is based on a single case study. Thus, generalization to other enterprises is limited. The authors invite further research focused on different types of enterprises. The methodology and the tools could be modified to suit a variety of contexts.

Author Contributions: Y.-S.L., writing—original draft, writing-review \& editing; M.C., conceptualization, supervision. Both authors have read and agreed to the published version of the manuscript.

Funding: This research received no external funding.

Institutional Review Board Statement: Not applicable.

Informed Consent Statement: Not applicable.

Conflicts of Interest: The authors declare no conflict of interest regarding to the publication of this paper.

\section{References}

1. Hilletofth, P.; Reitsma, E.; Eriksson, D. Coordination of new product development and supply chain management. In Innovation and Supply Chain Management: Relationship, Collaboration and Strategies; Springer: Cham, Switzerland, 2018; pp. 33-50. [CrossRef]

2. Krishnan, V.; Ulrich, K. Product development decisions: A review of the literature. Manag. Sci. 2001, 47, 1-21. [CrossRef]

3. Wheelwright, S.; Clark, K. Creating plans to focus product development. Harv. Bus. Rev. 1992, 70, 70-82. [PubMed]

4. Ellram, L.M.; Stanley, L.L. Integrating strategic cost management with a 3DCE environment: Strategies, practices, and benefits. J. Purch. Supply Manag. 2008, 14, 180-191. [CrossRef] 
5. Marsillac, E.; Roh, J.J. Connecting product design, process and supply chain decisions to strengthen global supply chain capabilities. Int. J. Prod. Econ. 2014, 147, 317-329. [CrossRef]

6. Sansone, S.; Hilletofth, P.; Eriksson, D. Critical operations capabilities for competitive manufacturing: A systematic review. Ind. Manag. Data Syst. 2017, 117, 801-837. [CrossRef]

7. Childerhouse, P.; Aitken, J.; Towill, D. Analysis and design of focused supply chain. J. Oper. Manag. 2002, 20, 675-689. [CrossRef]

8. Vonderembse, M.A.; Uppal, M.; Huang, S.H.; Dismukes, J.P. Designing supply chains: Towards theory development. Int. J. Prod. Econ. 2006, 100, 223-238. [CrossRef]

9. Simpson, B.K.; Schaefer, J.D. Systematic design method for large-scale manufacturing of fabricated polymers. In Proceedings of the ASME 2009 International Design Engineering Technical Conferences and Computers and Information in Engineering Conference, DETC2009-86745, San Diego, CA, USA, 30 August-2 September 2009; pp. 541-552.

10. Ma, J.H.; Tam, R.H. Creative design by integrating TRIZ and ABD. J. Eng. Des. 2006, 13, 193-198.

11. Stratton, R.; Mann, D. Systematic innovation and the underlying principles behind TRIZ and TOC. J. Mater. Process. Technol. 2003, 139, 120-126. [CrossRef]

12. Kim, J.; Kim, J.; Lee, Y.; Lim, W.; Moon, I. Application of TRIZ creativity intensification approach to chemical process safety. J. Loss Prev. Process Ind. 2009, 22, 1039-1043. [CrossRef]

13. Yang, C.J.; Chen, J.L. Accelerating preliminary eco-innovation design for products that integrates case-based reasoning and TRIZ method. J. Clean. Prod. 2011, 19, 998-1006. [CrossRef]

14. Petkovic, D.; Issa, M.; Pavlovic, N.D.; Zentner, L. Application of the TRIZ creativity enhancement approach to the design of a passively adaptive compliant robotic gripper. Assem. Autom. 2013, 33, 231-239. [CrossRef]

15. Shen, Y.T.; Shana, S. Product Redesign Using TRIZ and Contradictive Information from the Taguchi Method. In Proceedings of the 16th ISPE International Conference on Concurrent Engineering, Global Perspective for Competitive Enterprise, Economy and Ecology; Springer: Berlin/Heidelberg, Germany, 2009; pp. 487-497.

16. Lin, S.Y.; Wu, C.T. Application of TRIZ inventive principles to innovate recycling machine. Adv. Mech. Eng. 2016, 8950, 1-8. [CrossRef]

17. Mann, D. Physical Contradictions: Solving or Managing? Triz J. 2019. Available online: https://triz-journal.com/physicalcontradictions-solving-or-managing/ (accessed on 12 February 2021).

18. Terninko, J. 40 Inventive Principles with Social Examples. Triz J. 2001. Available online: https://triz-journal.com/40-inventiveprinciples-social-examples / (accessed on 12 February 2021).

19. Mann, D.L. Hands on Systematic Innovation for Business and Management; IFR Consultants Ltd.: Reigate, UK, 2004.

20. Retsptor, G. 40 Inventive Principles in Quality Management. Triz J. 2003. Available online: https://triz-journal.com/40-inventiveprinciples-quality-management/ (accessed on 12 February 2021).

21. Retsptor, G. 40 Inventive Principles in Marketing, Sales and Advertising. Triz J. 2005. Available online: https://triz-journal.com/ 40-inventive-principles-marketing-sales-advertising/ (accessed on 12 February 2021).

22. Zhang, J.; Chai, K.; Tan, K. 40 Inventive Principles with Applications in Service Operations Management. Triz J. 2003. Available online: https:/ / triz-journal.com/40-inventive-principles-applications-service-operations-management/ (accessed on 12 February 2021).

23. Ilevbare, I.M.; Probert, D.; Phaal, R. A review of TRIZ, and its benefits and challenges in practice. Technovation 2013, 22, 30-37. [CrossRef]

24. Movarrei, R.; Vessal, S.R. Theory of inventive problem solving (TRIZ) applied in supply chain management of petrochemical projects. In Proceedings of the 2007 IEEE International Conference on Industrial Engineering and Engineering Management, Singapore, 2-5 December 2007; pp. 1624-1628.

25. Petersen, K.J.; Handfield, R.B.; Ragatz, G.L. Supplier integration into new product development: Coordinating product, process and supply chain design. J. Oper. Manag. 2005, 23, 371-388. [CrossRef]

26. Christopher, M.C.; Lowson, R.; Peck, H. Creating agile supply chains in the fashion industry. Int. J. Retail. Distrib. Manag. 2004, 32, 367-376. [CrossRef]

27. Pero, M.; Abdelkafi, N.; Sianesi, A.; Blecker, T. A framework for the alignment of new product development and supply chains. Supply Chain Manag. Int. J. 2010, 15, 115-128. [CrossRef]

28. Lee, H.; Sasser, M. Product universality and design for supply chain. Prod. Plan. Control 1995, 6, 270-277. [CrossRef]

29. Huang, G.; Zhang, X.Y.; Liang, L. Towards integrated optional configuration of platform products, manufacturing processes, and supply chains. J. Oper. Manag. 2005, 23, 267-290. [CrossRef]

30. Blackhurts, J.; Wu, T.; O'Grady, P. PCDM: A decision support modeling methodology for supply chain, product and process design decision. J. Oper. Manag. 2005, 23, 325-343. [CrossRef]

31. Novak, S.; Eppinger, S. Sourcing by design: Product complexity and the supply chain. Manag. Sci. 2001, 47, 189-204. [CrossRef]

32. Feitzinger, E.; Lee, H.I. Mass customization at Hewlett Packard: The power of postponement. Harv. Bus. Rev. 1997, 75, 116-121.

33. Fisher, M. What is the right supply chain for your product? Harv. Bus. Rev. 1997, 75, 105-117.

34. Salvador, F.; Forza, C.; Rungtusanatham, M. Modularity, product variety, production volume, and component sourcing: Theorizing beyond generic prescriptions. J. Oper. Manag. 2002, 20, 549-575. [CrossRef]

35. Fine, C. Clockspeed: Winning Industry Control in the Age of Temporary Advantage; Perseus Books: New York, NY, USA, 1995.

36. Sturgeon, T. Modular production networks: A new American model of industrial organization. Ind. Corp. Chang. 2002, 11, 451-496. [CrossRef] 
37. Doran, D. Rethinking the supply chain: An automotive perspective. Supply Chain Manag. Int. J. 2004, 9, 102-109. [CrossRef]

38. Ro, Y.; Liker, J.K.; Fixon, S. Modularity as a strategy for supply chain coordination: The case of US Auto. IEEE Trans. Eng. Manag. 2007, 54, 172-189. [CrossRef]

39. Lau, A.; Yam, R. A case study of product modularization on supply chain design and coordination in Hong Kong and China. J. Manuf. Technol. Manag. 2005, 16, 432-446. [CrossRef]

40. MacDuffie, J.P.; Seturanan, K.; Fisher, M. Product variety and manufacturing performance: Evidence from the international automotive assembly plant study. Manag. Sci. 1996, 42, 350-369. [CrossRef]

41. Miller, J.; Vollmann, T. The hidden factory. Harv. Bus. Rev. 1985, 63, 142-150.

42. Fisher, M.; Ittner, C. The impact of product variety on automobile assembly operations; empirical evidence and simulation analysis. Manag. Sci. 1999, 45, 771-786. [CrossRef]

43. Brun, A.; Capra, E.; Miragliotta, C. Behavioural costs in manufacturing: How to balance standardization and variety costs. In Proceedings of the XIV International Working Seminar on Production Economics, Innsbruck, Austria, 22-26 February 2006.

44. Garcia, R.; Calantone, R. A critical look at the technological innovation typology and innovativeness terminology: A literature review. J. Product Innovat. Manag. 2002, 19, 110-132. [CrossRef]

45. Huang, S.; Uppal, M.; Shi, J. A product-driven approach to manufacturing supply chain selection. Supply Chain Manag. Int. J. 2002, 7, 189-199. [CrossRef]

46. Sanderson, S.W.; Uzumeri, M. Managing Product Families; Irwin Professional Pub.: Burr Ridge, IL, USA, 1997.

47. Ye, Y.; Huo, B.; Zhang, M.; Wang, B.; Zhao, X. The impact of modular designs on new product development outcomes: The moderating effect of supply chain involvement. Supply Chain Manag. Int. J. 2018, 23, 444-458. [CrossRef]

48. Pil, F.K.; Cohen, S.K. Modularity: Implications s for imitation, innovation, and sustained advantage. Acad. Manag. Rev. 2006, 31, 995-1011. [CrossRef]

49. Fisher, M.; Ramdas, K.; Ulrich, K. Component sharing in the management of product variety: A study of automotive braking system. Manag. Sci. 1999, 45, 297-315. [CrossRef]

50. Pil, F.; Holweg, M. Linking product variety to order-fulfillment strategies. Interfaces 2004, 34, 394-403. [CrossRef]

51. Berry, M. Strategic planning in small high tech companies. Long Range Plan. 1998, 31, 455-466. [CrossRef]

52. Vickery, S.K.; Koufteros, X.; Dröge, C.; Calantone, R. Product modularity, process modularity, and new product introduction performance: Does complexity matter? Prod. Oper. Manag. 2016, 25, 751-770. [CrossRef]

53. Porter, M.E. Competitive Strategy; Free Press: New York, NY, USA, 1980.

54. Lee, K.; Lim, G.; Tan, S. Dealing with resource disadvantage: Generic strategies for SMEs. Small Bus. Econ. 1999, 12, $299-311$. [CrossRef]

55. Gourova, E. Knowledge management strategy for small and medium enterprises. Proc. Int. Conf. Appl. Comput. Sci. 2010, 2010, 639-648.

56. Levy, M.; Powell, P.; Yetton, P. SMEs aligning IS and the strategic context. J. Inf. Technol. 2001, 16, 133-144. [CrossRef]

57. Smith, M.J. Social Science in Question; Sage: London, UK, 1998.

58. Cooper, R.G. Stage-gate systems: A new tool for managing new products. Bus. Horiz. 1990, 33, 44-54. [CrossRef]

59. Ulrich, K.T.; Eppinger, S.D.; Yang, M.C. Product Design and Development, 7th ed.; McGraw-Hill: New York, NY, USA, 2020.

60. Thongprasert, A.; Jiamsanguanwong, A. New Product Development Process for IOT-Enabled Home Use Medical Devices: A2Systematic Review. Eng. J. 2021, 25, 15-48.

61. Cooper, R.G.; Kleinschmidt, E.J. An investigation into the new product process; steps, deficiencies, and impact. J. Prod. Innov. Manag. 1986, 3, 71-85. [CrossRef]

62. Cooper, R.G. What's next? After stage gate. Res. Technol. Manag. 2014, 57, 20-31. [CrossRef]

63. Sommer, A.F.; Hedegaard, C.; Dukovska-popovska, I.; Steger-Jensen, K. Improved product development performance through agile/stage-gate hybrids. Res. Technol. Manag. 2014, 58, 34-44. [CrossRef]

64. Papanek, V. Design for the Real World: Human Ecological and Social Change; Academy Edition: Chicago, IL, USA, $1972 ;$ p. 322.

65. Pierre, D.L.; Alain, D. Integrated Design of a Product Family and Its Assembly System; Springer Science \& Business Media: Berlin/Heidelberg, Germany, 2011.

66. Chedmail, P.; Cognet, G.; Fortin, C.; Mascle, C.; Pegna, J. Integrated Design and Manufacturing in Mechanical Engineering. In Proceedings of the Third IDMME Conference Held in Montreal, Canada, May 2000; Springer Science \& Business Media: Berlin/Heidelberg, Germany, 2013. 